Progress in Nuclear Science and Technology

Volume 6 (2019) pp. 175-180

\title{
ARTICLE
}

\section{The latest estimation for the parameter $\alpha$ value of radiation protection optimization in China}

\author{
Jia Linsheng*, Yang Yapeng, Feng Zongyang, Xu Xiaoxiao and Zhang Jiangang \\ China Institute for Radiation Protection, Taiyuan City of China
}

\begin{abstract}
In the radiation protection optimization analysis, $\alpha$ value is the most basis and important parameter. At present, the expression of $\alpha$ value in the ICRP publish 101 is mainly adopted, it consists of $\alpha$ basis value $\left(\alpha_{0}\right)$ and radiation risk aversion factor (a). The main idea of the paper to estimate $\alpha$ basis value is based on the economic value of life, and combining the loss of the health detriment cost of radiation. The paper adopts three methods to estimate $\alpha$ basis value according to the current situation of China: 1.Based on gross domestic product (GDP), 2.Based on regulations of government agencies, 3.Based on willingness method. $\alpha$ value has the relation with economy, politics, social psychology of the nation and so on, and there many methods to estimate it, each method has its merits and demerits. The decision maker should select the reasonable $\alpha$ value according to the situation of the nation. At present, China's economy has been developed rapidly, the indexes related to economy and society have been changed significantly, so $\alpha$ value of previous can't reflect current situation, it need to recalculate and adjust.
\end{abstract}

\section{Keywords: optimization analysis; $\alpha$ basis value; radiation risk aversion}

\section{Introduction}

Optimization analysis is one of three principles of radiation protection. In the radiation protection optimization analysis, the most important thing is to analyze $\alpha$ value in fact, $\alpha$ value is specified the value of 1 person - Sv. It is inevitable in the quantitative process of the radiation detriment. Because the costs of reaching a certain radiation protection level at different economic levels are difference, so $\alpha$ value is closely related to the level of national economy.

Our country has already made some foundation research about optimization parameter analysis of radiation protection. In the 90 s of the 20th century, Zhang $\mathrm{Li}$ and others have made a preliminary study about $\alpha$ value [1] using the data of ICRP 60 report. The main idea of them is thought estimating the costs of fatal cancers, nonfatal cancer and serious genetic disease induced by radiation, to estimate $\alpha$ value. The article published by Li Chunhai summarized several methods about $\alpha$ value estimation [2], and used the GDP method to estimate $\alpha$ value [3] of radiation protection optimization in China.

Because of the fast economic development of our country, especially in recent ten years, $\alpha$ value estimated by previous is not suit to the current situation, it should be updated. According to the current economic of our country, the paper adopts three methods to estimate new $\alpha$ value of our country.

*Corresponding author. Email: jialinsheng2008@126.com

\section{Cost-benefit analysis}

Cost-benefit analysis is derived from the economics theory, it may be the most direct method of quantitative aid decision methods, and used to compare the benefits and detriments brought by different decisions. The main characteristic of cost - benefit analysis is that all factors affected decision-making are quantified by monetary.

The whole expression of cost-benefit analysis [4] in radiation protection can be descripted by:

$\mathrm{B}=\mathrm{V}-(\mathrm{P}+\mathrm{X}+\mathrm{Y})$

where, $\mathrm{B}$ is net benefit brought from some practice; $\mathrm{V}$ is gross benefit brought from some practice; $\mathrm{P}$ is base product cost, not including radiation protect cost; $\mathrm{X}$ is radiation protection cost in order to arrival some protection level; $\mathrm{Y}$ is detriment cost to the selected radiation protection level.

In formulation (1), only variation $\mathrm{X}$ and variation $\mathrm{Y}$ have the relation with collective dose $\mathrm{S}$, so cost-benefit analysis of radiation protection optimization can be summarized as selecting the best combination of radiation protection cost $\mathrm{X}$ and radiation detriment cost $Y$. In practice, protection cost $\mathrm{X}$ usually can be quantified by monetary, so if there is a relationship between the radiation detriment cost $\mathrm{Y}$ and monetary amount, the total cost $(\mathrm{X}+\mathrm{Y})$ can be the quantified, and analysis made by decision makers becomes relatively easy. Figure 1 shows using the cost-benefit analysis to select the optimum solution [5] in radiation protection. 


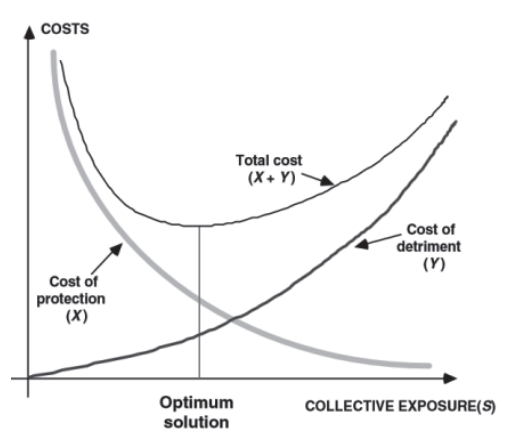

Figure 1. Select optimum solution using cost-benefit analysis method.

If total cost $(\mathrm{X}+\mathrm{Y})$ is continuous change with the collective dose $\mathrm{S}$, then the optimum solution meets the condition $\mathrm{d}(\mathrm{X}+\mathrm{Y}) / \mathrm{dS}=0[6]$, and exist the value $\mathrm{S}_{0}$, when $\mathrm{S}=\mathrm{S}_{0}$, satisfy:

$$
\left(\frac{d X}{d S}\right)_{S_{0}}=-\left(\frac{d Y}{d S}\right)_{S_{0}}
$$

where, $\mathrm{S}_{0}$ is Collective dose corresponding to optimum solution of radiation protection.

From the expression (2), when the radiation protection solution is optimum solution, the increased cost of radiation protection corresponding to decreased the unit collective dose equal to the decreased detriment cost which brought by decreasing the unit collective dose.

\section{Radiation detriment cost}

Radiation detriment expression is proposed by the ICRP publication No. 101 is the latest. IAEA Safety Report Series No.21 also used this expression, the expression [7] as follow:

$$
\mathrm{Y}=\sum \alpha_{j} S_{j}
$$

where, $\mathrm{Y}$ is radiation detriment cost; $\alpha_{j}$ is monetary equivalent value of 1 person $\bullet \mathrm{Sv}$ in group $\mathrm{j} ; S_{j}$ is collective dose in group $\mathrm{j}$.

Population groups divided depends on exposure types, expose time, and individual dose level. Different groups should adopt different monetary equivalent value of 1 person•Sv.

The expression for estimating $\alpha$ base value [7] is:

$$
\alpha_{r e f}(d)=\alpha_{b a s e}\left(\frac{d}{d_{0}}\right)^{a}
$$

where, $\alpha_{r e f}(d)$ is reference monetary value to 1 person $\bullet \mathrm{Sv}$ under individual radiation level $\mathrm{d} ; \alpha_{\text {base }}$ is monetary equivalent value of one unit collective dose; $\mathrm{d}$ is individual radiation level; $d_{0}$ is the minimum individual dose is acceptable in the range of aversion to individual dose, and usually using the limit value of public annual effective dose $(1 \mathrm{mSv} / \mathrm{a})$, this means $d_{0}=1 \mathrm{mSv} / \mathrm{a} ; a$ is radiation risk aversion coefficient, it reflects people's aversion degree to accepted individual radiation dose levels, and it will increase with the aversion degree becoming bigger.

From the expression (4), $\alpha_{r e f}(d)$ is $\alpha$ reference value, which has the relation with $\alpha$ base value, individual dose, and radiation risk aversion coefficient, it can be clearly descripted in Figure 2 [7].

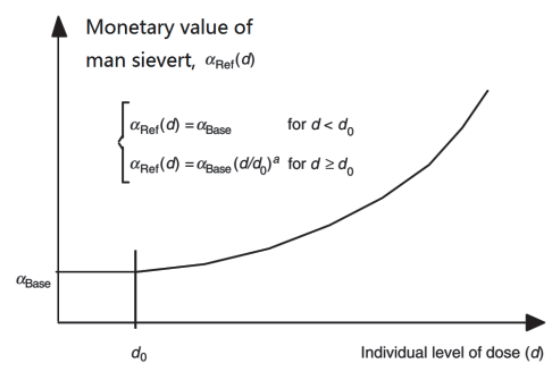

Figure 2. $\alpha$ reference value.

From Figure 2, $\alpha$ value actually is $\alpha$ reference value, which has function relation with individual dose level. When individual dose level $d$ is less than the acceptable level of dose $d_{0}, \alpha$ value is equal to $\alpha$ base value; when $d$ above than $d_{0}$, $\alpha$ value should consider radiation risk aversion degree under different individual dose level. Because different groups with different individual dose usually have different radiation risk aversion degree, different groups use different $\alpha$ value.

In ICRP publication No. 101, when dose level under $1 \mathrm{mSv}$, radiation risk aversion coefficient $a$ is 1 ; when the dose level was greater than $1 \mathrm{mSv}, a$ is a value between 1.2-1.8 [7], this recommended $a$ is not good used in practical application. Radiation risk aversion coefficient $a$ recommended by Nuclear Protection Evaluation Centre (CEPN) can be good used in application, the specific values are shown in Table 1, the value is between 1.2 and 1.75 [8].

Table 1. Radiation risk aversion coefficient a to radiation levels [8].

\begin{tabular}{ccccc}
\hline "a" & 1 & 1.2 & 1.6 & 1.75 \\
\hline $\begin{array}{c}\text { Dose level } \\
(\mathrm{mSv})\end{array}$ & $0-1$ & $1-5$ & $5-15$ & $15-50$ \\
\hline
\end{tabular}

\section{4. $\alpha$ base value estimation}

At present, a popular idea to estimate $\alpha$ base value is through directly or indirectly estimating individual life economic value, and combining the average life, to estimate it [2]. The process of the idea can be seen in Figure 3. The paper uses this idea to estimate $\alpha$ base value.

IAEA SRS No. 21 report adopts human capital method to estimate $\alpha$ base value [9]. The method uses two parameter values related to radiation as follows.

1. Average loss of life expectancy associated with radiation induced health effect (fatal cancers and 


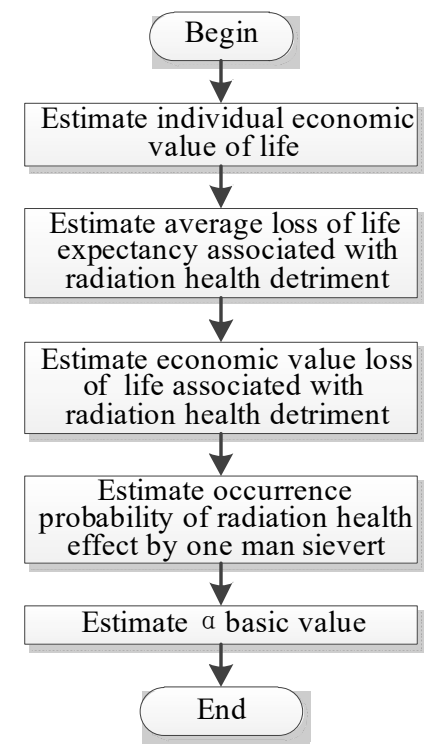

Figure 3. $\alpha$ base value estimation process.

hereditary effects): 16 years [9];

2. Probability of the occurrence of radiation induced health effect for workers: $5.6 \times 10^{-2} \mathrm{~Sv}[9,10]$, which comes from ICRP No.103 publication.

The paper adopts above two parameter values to estimate $\alpha$ base value.

There are several methods to estimate $\alpha$ base value, the paper uses three kinds of methods to estimate it: 1.Based on gross domestic product (GDP); 2.Based on national regulation compensation; 3.Based on willingness method.

\subsection{Based on GDP to estimate a base value}

Based on GDP to estimate $\alpha$ base value is a tradition method, many countries have used it to estimate $\alpha$ base value. Actually, the method belongs to human-capital method.

The steps of based on GDP to estimate $\alpha$ base value as follows:

1. According to official website of the national bureau of statistics, per capita gross domestic products in 2016 is $\mathrm{G}=\mathrm{RMB} 53980$ [16];

2. Average loss of life expectancy associated with radiation induced health effect is $\mathrm{L}=16$ years;

3. Probability of the occurrence of radiation induced health effect for workers is $\mathrm{P}=5.6 \times 10^{-2} \mathrm{~Sv}^{-1}$;

4. $\alpha$ base value in 2016 is $\alpha_{b a s e}$ :

$$
\begin{aligned}
\alpha_{b \text { ase }} & =\mathrm{G} \times \mathrm{L} \times \mathrm{P}=53980 \times 16 \times 5.6 \times 10^{-2} \\
& \approx \mathrm{RMB} 49,000 /(\text { person } \cdot \mathrm{Sv})
\end{aligned}
$$

\subsection{Based on nation regulations compensation to estimate a basis value}

According to the 39th provision of "Work-related Injury Insurance Regulation", worker death compensation includes three parts: 1 . One-time occupational injury subsidy; 2. Funeral grants; 3.
Pension for making offering to relatives. Individual economic value of life should include the three parts.

(1) One-time occupational injury subsidy

The standard of one-time occupational injury subsidy is 20 times of per capita disposable income on nationwide cities and town last year. According to the data from Chinese Statistical yearbook 2015, per capita disposable income on nationwide cities and town in 2014 is $\mathrm{DI}=\mathrm{RMB} 28843.9$, so one-time occupational injury subsidy in 2015 is M1:

$$
\mathrm{M} 1=\mathrm{DI} \times 20=28843.9 \times 20=\mathrm{RMB} 576878
$$

(2) Funeral grants

The standard of Funeral grants for 6 month wages based on staff's mean monthly wages on overall region last year. Considering each region is different, the paper using average annual wages of employed persons of nationwide cities and towns to estimate funeral grants. According to Chinese Statistical yearbook 2015 [11], average annual wages of employed persons of nationwide cities and towns in 2014 is $\mathrm{AW}=\mathrm{RMB}$ 56360 , so funeral grants in 2015 is M2:

$$
\mathrm{M} 2=\mathrm{AW} \times 0.5=56360 \times 0.5=\mathrm{RMB} 28180
$$

(3) Pension for making offering to relatives

According to the standard, issued verification pension every month for make offerings to relatives should not be higher than the dead worker's wages. The paper uses the dead worker's wages to estimate pension for making offering to relatives.

According to Chinese Statistical yearbook 2016 [12], average annual wages of employed person of nationwide cities and towns in 2015 is RMB 62029. The paper uses this data as the average annual wages (W) of dead worker before death.

According to Chinese Statistical yearbook 2016, average life expectancy in 2015 is $\mathrm{E}=75$.46years.

In our country the legal beginning working age is 16 years old, and retirement age usually is 60 years old. Taking middle value method to roughly estimating average age of occupational injury death is $\mathrm{E}_{\mathrm{d}}=38$ years. Although the value is smaller than reality, considering the data can't find from research literature, the paper uses the data.

Using above data, rough estimating pension for making offering to relatives is M3:

$$
\begin{aligned}
\mathrm{M} 3 & =\mathrm{W} \times\left(\mathrm{E}-\mathrm{E}_{\mathrm{d}}\right)=56360 \times(76.34-38) \\
& \approx \mathrm{RMB} 2160842.4
\end{aligned}
$$

The steps of based on national regulations to estimate $\alpha$ base value as follows:

1. Occupational injury death subsidy in 2015 is M:

$M=M 1+M 2+M 3=R M B 2765900.4$

2. Rough estimating average age of occupational 
injury death is $\mathrm{E}_{\mathrm{d}}=38$ years;

3. According to Chinese Statistical yearbook 2016, average life expectancy in 2015 is $\mathrm{E}=76.34$ years;

4. $\alpha$ base value in 2015 is $\alpha_{b \text { ase }}$ :

$$
\begin{gathered}
\alpha_{\text {base }}=\frac{\mathrm{M} \times \mathrm{L} \times \mathrm{P}}{\mathrm{E}-\mathrm{E}_{\mathrm{d}}}=\frac{2765900.4 \times 16 \times 5.6 \times 10^{-2}}{76.34-38} \\
\approx \mathrm{RMB} 65,000 /(\text { person } \bullet \mathrm{Sv})
\end{gathered}
$$

\subsection{Based on willingness method to estimate $\alpha$ base value}

At present, based on willingness method [2] to estimate individual economic value of life is becoming a tendency. Willingness includes two respects. One is willingness to accept (WTA), and anther is willingness to pay (WTP). The concept of WTA can be briefly descripted by willing to accept a certain amount of compensation for the risk. The concept of WTP can be briefly descripted by willing to pay a certain amount to avoid the death.

Willingness method has three types: wages-risk method, consumption market method, and conditional value method. There are two merits [13] based on wages-risk method comparing with others: 1 . Wages and risk data are relatively easy to acquire; 2 . It depends on real market, not hypothetical market. The paper uses wages-risk method to estimate individual economic value of life.

Wage risk method is using the phenomenon of high wages in the labor market corresponding to high risk of death, through regression model controlling other variables, identify the wages difference reasons based on the risk, then to estimate individual life economic value.

Usually Wage-risk method is constructed by regression model, which wages as the dependent variable, the risk of death as independent variables. Generally logarithmic linear model is adopted to construct it. Such as formula (11) [14]:

$$
\ln W=f(R, S, D, e)
$$

where, $\mathrm{W}$ is wages level; $\mathrm{R}$ is post death risk (death toll/ten thousand); $\mathrm{S}$ is characteristic variables on workers; D is characteristic variables on posts; e is error term.

The model assumes that post death risk coefficient is $\beta$, post death risk is $\mathrm{R}_{0}$ and initial wages is $\mathrm{W}_{0}$ under initial condition, other factors remain unchanged. If post death risk increased $\Delta \mathrm{R}$, variation of wages as follows [14]:

$$
\Delta W=W_{0} e^{\beta \Delta \mathrm{R}}-W_{0}
$$

Under the model, individual life economic value is:

$$
\mathrm{V}=W_{0} \frac{e^{\beta \Delta \mathrm{R}_{-1}}}{\Delta \mathrm{R}} \times 10^{4} \approx W_{0} \times \beta \times 10^{4}
$$

In 2012, Mei Qiang and others adopt wages-risk method to design the questionnaires [13], and investigating 98 companies and 795 employees. The investigation industries are including service industry, construction industry, chemical industry, manufacturing industry and coal industry. The investigation staffs are including on-site staffs, on-site management staffs, general administration staffs and administration management staffs. By investigating expected addition wages corresponding to the increased death risk additional wages, to estimate life economic value of employees surveyed. The mathematical analysis to the survey shows that individual life economic value obeys normal distribution, and under the confidence level of $95 \%$, average life economic value of the willingness to accept is RMB 38,544,000 [13].

\subsubsection{Based on WTA to estimate $\alpha$ basis value}

The step of based on WTA to estimate $\alpha$ basis value as follows:

1. Individual life economic value of the willingness to accept is $\mathrm{M}=\mathrm{RMB} 38,544,000$;

2. According to Chinese Statistical yearbook 2016, average life expectancy in 2012 is $\mathrm{E}=75.46$ years;

3. $\alpha$ basis value in 2012 is $\alpha_{\text {base }}$ :

$$
\begin{aligned}
\alpha_{b \text { ase }} & =\mathrm{M} \times \mathrm{L} \times \mathrm{P} \div \mathrm{E} \\
& =38,544,000 \times 16 \times 5.6 \times 10^{-2} \div 75.46 \\
& \approx \mathrm{RMB} 458,000 /(\text { person } \bullet \mathrm{Sv})
\end{aligned}
$$

\subsubsection{Based on WTP to estimate $\alpha$ basis value}

Using WTP to estimate $\alpha$ basis value, only individual life economic value is difference comparing with WTA. According to the article publish by Horowitz and McConnell [15], in the investigation on WTP and WTA finding that the person surveyed easily to be motived to demand relatively high WTA value due to implying abandoning some rights, and consider average WTA value is 7 times to average WTP value. So the average life economic value of WTP is $\mathrm{M} 1=38,544,000 / 7 \approx$ RMB 5,506,300.

$\alpha$ basis value in 2012 is $\alpha_{b \text { ase }}$ :

$$
\begin{aligned}
\alpha_{b \text { ase }} & =\mathrm{M} 1 \times \mathrm{L} \times \mathrm{P} \div \mathrm{E} \\
& =5,506,300 \times 16 \times 5.6 \times 10^{-2} \div 75.46 \\
& \approx \mathrm{RMB} 66,000 /(\text { person } \bullet \mathrm{Sv})
\end{aligned}
$$

\section{Summary}

$\alpha$ base value reflects the economic cost level to reduce the unit collective dose during a certain period, therefore determining it should to consider the country's economic level in different periods. Countries with economic level growing fast, especially developing countries, needs to updated $\alpha$ base value regularly. Our country is a developing country, with the rapid economic development, $\alpha$ base value researched in the 1990s has not apply to the present, it is necessary to update $\alpha$ base value according to current economy condition. It is necessary to update $\alpha$ basic value 
according to current economy condition. According to the current data in china, the paper uses three methods to estimate $\alpha$ base value, and results are shown in Table 2 .

Table 2. Three methods to estimate $\alpha$ base value.

\begin{tabular}{|c|c|c|c|c|}
\hline No. & \multicolumn{2}{|c|}{ Method } & Year & $\begin{array}{c}\alpha \text { basic value } \\
(\mathrm{RMB} / \text { person } \cdot \mathrm{Sv})\end{array}$ \\
\hline 1 & \multirow{2}{*}{\multicolumn{2}{|c|}{$\begin{array}{c}\text { GDP } \\
\text { Nation regulations } \\
\text { compensation }\end{array}$}} & 2016 & 49,000 \\
\hline 2 & & & 2015 & 65,000 \\
\hline 3 & Willingness & $\begin{array}{l}\text { WTA } \\
\text { WTP }\end{array}$ & $\begin{array}{l}2012 \\
2012 \\
\end{array}$ & $\begin{array}{c}458,000 \\
66,000 \\
\end{array}$ \\
\hline
\end{tabular}

According to the national economic and social development statistical bulletin about 2016 [16], the GDP growth rates in recent years are shown in Table 3.

Table 3. Growth rates in recent years.

\begin{tabular}{ccc}
\hline No. & Year & Growth rate(\%) \\
\hline 1 & 2012 & $7.9 \%$ \\
2 & 2013 & $7.8 \%$ \\
3 & 2014 & $7.3 \%$ \\
4 & 2015 & $6.9 \%$ \\
5 & 2016 & $6.7 \%$ \\
\hline
\end{tabular}

According the data publish on Sina.com, the average exchange rate for the dollar in 2016 was 6.4.

Using above data, converting $\alpha$ base value in Table 2 to $\alpha$ base value in 2016, the results are shown in Table 4 .

Table 4. $\quad \alpha$ base value in 2016 .

\begin{tabular}{|c|c|c|c|}
\hline \multicolumn{2}{|c|}{ Method } & $\begin{array}{c}\alpha \text { base value } \\
(\mathrm{RMB} / \text { person } \cdot \mathrm{Sv})\end{array}$ & $\begin{array}{c}\alpha \text { base value } \\
(\$ / \text { person } \cdot S v) \\
\end{array}$ \\
\hline \multirow{2}{*}{\multicolumn{2}{|c|}{$\begin{array}{c}\text { GDP } \\
\text { Nation regulations } \\
\text { compensation }\end{array}$}} & 49,000 & 7,700 \\
\hline & & 69,000 & 10,800 \\
\hline Willingness & $\begin{array}{l}\text { WTA } \\
\text { WTP }\end{array}$ & $\begin{array}{c}605,000 \\
87,000\end{array}$ & $\begin{array}{l}94,600 \\
13,600\end{array}$ \\
\hline
\end{tabular}

Each method to estimate $\alpha$ base value has its own advantages and disadvantages. Based on GDP to estimate $\alpha$ base value is generally low, and its result should be the lower bound, because its method without considering the economic cost by medical treatment. Based on the national regulations compensation to estimate $\alpha$ base value, partly reflects the people's recognition to economic value of life under present social, but its update speed slow, and not considering the worker's wages will increase in the following years and other factors, so its result should be the lower bound. Using willingness method to estimate $\alpha$ base value, in WTA respect, people usually tend to overvalue individual economic value of life; and in WTP respect, people usually tend to underestimate individual economic value of life. So the real individual economic value of life should between WTP and WTA.

According above analysis, the paper thinks the reasonable $\alpha$ base value should be range from $\$ 13,600 \sim$
$\$ 94,600$, and generally its result should be integer, so the result should be between $\$ 14,000 \sim \$ 95,000$.

In ICRP publication No. 37, recommended $\alpha$ base value is between $\$ 10,000 \sim 20,000$. In IAEA SRS No. 21 report, $\alpha$ base value estimated by human capital approach is about $\$ 20,000$, and the report lists recommended values by nine European and American countries, most of them the recommended alpha value is between $\$ 10,000 \sim \$ 270,000$, only Switzerland is \$3 million.

Above $\alpha$ base values are related to nation's economic levels and other factors, so $\alpha$ base value should suit to nation's reality condition. Under current situation in china, the reasonable $\alpha$ base value should be between $\$ 14,000 \sim \$ 95,000$. Considering economic level of china is developing relative rapidly, and GDP growth rate exceeding $6.5 \%$ every year in recent years, and it will continue, so in future $\alpha$ base value also need to be update.

\section{References}

[1] Z. Li, X. Yihua, et al., Primary research on $\alpha$ value of radiation detriment cost, Radiation Protecion [J], (1995). [Chinese]

[2] C. Li, $\alpha$ base value estimation of radiation protection, China's Radiation Health [J], (2000). [Chinese]

[3] C. Li, Using GDP method to estimate our country's $\alpha$ base value $\left(\alpha_{0}\right)$ of radiation protection, China's Radiation Health [J], (2002). [Chinese]

[4] ICRP, Cost-benefit analysis in the optimization of radiation protection, ICRP Publish 37, Ann. (1985).

[5] ICRP, Assessing dose of the representative person for the purpose of radiation protection of the public, ICRP Publish 101, Ann. (2006).

[6] K. Yang, X. Feng, et al., Cost-benefit analysis in radiation protection optimization, China's Health Economic (2009). [Chinese]

[7] ICRP, The optimization of radiological protection-broadening the process, ICRP Publish 101b. Ann. (2005).

[8] B.I. Lee, D.H. Suh, et al., The Monetary Value of the Man-Sv for Korean Npp Radiation Workers Assessed by the Radiation Aversion Factor, Radiation Health Research Institue, Korea Hydro \& Nuclear Power Co.,Ltd., .

[9] International Atomic Energy Agency, Optimization of radiation protection in the control of occupational exposure, Safety Reports Series No.21, Vienna, (2002).

[10]ICRP, The 2007 recommendation of the international commission on radiological protection, ICRP Publish 103, Ann. (2007).

[11]The National Bureau of Statistics of the People's Republic of China, Chinese Statistical Yearbook 2015. http://www.stats.gov.cn/tjsj/ndsj/2015/.

[12] The National Bureau of Statistics of the People's Republic of China, Chinese Statistical Yearbook 
2016. http://www.stats.gov.cn/tjsj/ndsj/2016/.

[13]M. Qiang, et al., Based on wages-risk method to estimate life value, Journal of China Safety Science [J], (2012). [Chinese]

[14] S. Liu and G. Song, Meta analysis of based on wages-risk method to estimate life value, China Price [J]. (2015).
[15]J.k. Horowitz and K.E. McConnell, A review of WTA/WTP studies, Journal of Environmetal Economics and Management, (2002).

[16]RPC, The National Economic and Social Development Statistical Bulletin about 2016. http://www.stats.gov.cn/tjsj/tjgb/ndtjgb/201702/t20 170228_1467424.html. 